\title{
Discussion on Homogenization of Emergency Clinical Decision
}

\author{
Huijun Qi, Zhangshun Shen, Hui Guo, Jianguo Li \\ Department of Emergency Medicine, Hebei General Hospital, Shijiazhuang, China \\ Email:1ijg65@163.com
}

How to cite this paper: Qi, H.J., Shen, Z.S., Guo, H. and Li, J.G. (2020) Discussion on Homogenization of Emergency Clinical Decision. Open Journal of Internal Medicine, 10, 302-310.

https://doi.org/10.4236/ojim.2020.103031

Received: August 19, 2020

Accepted: September 26, 2020

Published: September 29, 2020

Copyright $\odot 2020$ by author(s) and Scientific Research Publishing Inc. This work is licensed under the Creative Commons Attribution International License (CC BY 4.0).

http://creativecommons.org/licenses/by/4.0/

(c) (i) Open Access

\begin{abstract}
The objective of this work is to explore how to realize the homogenization of emergency clinical decision, and it means that patients receive the same effect of clinical decisions and the treatment in a different hospital. In order to achieve that, emergency doctors should first have the same clinical thinking and thinking mode which is the biggest challenge for homogenization of emergency clinical decision. The task of emergency medicine is to give priority to the treatment of critically ill patients, so step-down thinking of "excluding life-threatening symptoms first" is the basis, the preemptive thinking is the means, and Process thinking is the key of homogenization; The initial diagnosis and treatment mode of symptom-oriented is the starting point for emergency decision; establishing a unified "checklist" can not only broaden the lateral thinking of emergency doctors, but also unify the thinking of differential diagnosis of emergency; dynamic observation should run through the whole diagnosis and treatment process, which is necessary for the homogenization of emergency decision.
\end{abstract}

\section{Keywords}

Clinical Decision, Medical Homogeneity, Step Down Thinking, Preemptive Examination, Process Thinking, Checklist

\section{Introduction}

The medical homogenization refers to the fact that in addition to hardware factors, such as equipment, buildings, etc. Within a certain scope, the clinical skills of the diagnosis and treatment of medical personnel are almost the same, and produce results essentially in the effect of medical services [1]. That is to say, patients can receive the same effect of medical services in a different hospital. Emergency Department is an interdisciplinary clinical discipline with a wide 
spectrum of diseases and a great unpredictability. The emergency physician must make the correct clinical decision quickly, the experience thinking pattern is essential, but it may also bring the inertia thinking leading to different outcomes [2]. In China, The important task of medical reform in the long term is to improve the system of tiered medical services, and the key of which is to realize medical homogenization [3]. The emergency department is the window of hospitals and the frontier of emergency medical assistance. To realize the homogenization of medical services effect is not only one of the focus problems in emergency medicine, but also an urgent requirement of medical reform in China.

This template, created in MS Word 2007, provides authors with most of the formatting specifications needed for preparing electronic versions of their papers. All standard paper components have been specified for three reasons: 1) ease of use when formatting individual papers, 2) automatic compliance to electronic requirements that facilitate the concurrent or later production of electronic products, and 3) conformity of style throughout a journal paper. Margins, column widths, line spacing, and type styles are built-in; examples of the type styles are provided throughout this document and are identified in italic type, within parentheses, following the example. Some components, such as multi-leveled equations, graphics, and tables are not prescribed, although the various table text styles are provided. The formatter will need to create these components, incorporating the applicable criteria that follow.

\section{Unified Thinking for Emergency Decision-Making}

Thinking has integrity and inertia, once thinking mode of a person is formed, shi/he will think in a fixed way, and influence her/his action at any time everywhere. Emergency doctors almost every day provide patients with decision-making. In order to implement the same effect of medical services, we must first have the same thinking mode of emergency decision-making. Only with the unity of emergency decision-making thinking mode can guarantee effect of medical services, and avoid the rigidity in the implementation of clinical pathway with different clinical situations, and finally achieve homogeneous medical results. Unified thinking for emergency decision-making is the biggest challenge for homogenization of emergency clinical decision.

\subsection{Step-Down Thinking}

Step-down Thinking was first put forward by Professor Wang Peiyan in the emergency field [4]. It refers to the exclusion of the patients' diseases in accordance with certain methods, from life-threatening diseases to general, from rapid progress ones to the slow, from organic to functional diseases. "Step-down Thinking" had been put forward more than ten years, some scholars think that it is too comprehensive and lack of obvious pertinence, and which waste the patient's time and money and maybe cause over-treatment [5]. In fact, this is a utilitarian view. Eeach life is unique and valuable and diffierent from property, in- 
terests, and which cannot be measured by utilitarianism [6]. The fundamental purpose of medicine is to maintain the patient's life, everyone has only one life. Therefore, in the course of medical activities, we should except life-threatening conditions first. Although life-threatening conditions usually are small-probability events, it is the black swans once happening. There were too many bloody lessons in the past. The emergency department is the place where the patient's life is saved, and there is more uncertainty before the diagnosis is made clearly [7]. The principle of common diseases and frequent diseases is at greater risk in emergency care. According to humanistic thought of "life first", ruling out the possibility of life-threatening conditions is the embodiment of Medical Humanities [6].

\subsection{Preemptive Thinking}

Preemptive thinking refers that not noly the preemptive treatment is given to critically ill patients after preliminary evaluation, but also "preemptive examination". For critically ill patients, time is life. In the emergency field, there is a say of "first shoot, then aim at it", that means abnormal pathophysiological condition in the patients should be "shot" quickly, not blindly deal with. It is also "aim at it first and then shoot" [8]. Accurate diagnosis is the premise of effective treatment. We first use appropriate and inexpensive laboratory tests and bedside examinations to find the pathophysiological changes in patients, and to identify potentially life-threatening diseases earlier, so as to achieve the purpose of saving lives fast. For example, we must identify the cause of shock first, because the treatment principle of different causes of shock is very different. If the patient can not be accurately judged the pathophysiological state first, it will become blind shooting, which will cause great harm. In order to quickly understand the patient's pathophysiological condition, we need "preemptive examination". It is a supplement to Step-down thinking.

"Preventive examination" does not mean "spreading the net widly, nor blindly", but specifically excluding fatal diseases in patients around critical state. Especially some guiding auxiliary examinations are of great significance to the exclusion of disease categories. Such as: normal results of $\mathrm{D}$ dimer can be large probability except thrombotic disease, normal C-reactive protein (CRP) can almost rule all bacterial infection, normal brain natriuretic precursor (BNP) can basically except for cardiac insufficiency, etc [9]. The fundamental purpose of medicine is to save people, and do not harm the life of patients as the premise; Emergency doctors should give effective intervention to save lives first in the limited time. When rescuing patients, thinking about whether or not to do an experiment may delay the rescue time, and missed examination leading to missed diagnosis may threaten the life of patients.

\subsection{Process Thinking}

Whether we are in leisure or work, there is a sequence of "what to do first, then what to do, and finally what to do", which is what we call the process. Process 
thinking refers to the way of thinking in accordance with certain steps. It is based on structured thinking, sorts out all the activity steps and contents related to thinking, and then continuously optimizes the thinking process. Emergency doctors' initial thinking is always to consider: 1) predict the possibility of life-threatening in patients; 2) within a limited time window to take immediate measures to stabilize the condition or alleviate symptoms [5], According to this thinking process, a feasible implementation step is worked out (Table 1).

Process thinking was widely used in critical cases, and which effect is remarkable. The famous early goal-oriented treatment (EGDT) in sepsis is also the idea of Process thinking, although indicators of EGDT has been questioned, but Process thinking of EGDT is still popular, and play a good role. This is the charm of Process thinking. In fact, "step-down thinking and preemptive thinking" themself also have the connotation of Process thinking.

The more complex things need process, but it is more difficult to formulate specific workflow, only can we make up for the lack of specific workflow by process thinking. No process leads to confusion for complex things, and the experience can not maintain homogeneity and accumulation of which requires a long time. The complexity of medicine needs process thinking, and the urgency of emergency needs process thinking too.

Process thinking is based on structured thinking which focuses on results and ultimate goals, and emphasizes integrity and systematization. A report by the American Institute of Medicine more than 20 years ago, which a statistical analysis of medical errors was made, said that it was human nature to make mistakes, that the fundamental solution is to change the thinking, and to build a "no-fault" workflow and safety philosophy [10]. At present, the construction of chest pain center and stroke center has given us a lot of inspiration, and in which we grasp the key problems and links, step by step, improve work efficiency. Finally, medical errors are reduced, doctors' blind speculation and aimless vigilance are eliminated.

Table 1. Clinical decision-making thinking flow.

\begin{tabular}{|c|c|c|}
\hline & Thinking flow & Content of thinking \\
\hline 1 & Is this a serious patient? & $\begin{array}{l}\text { Symptomology to judge critical degree } \\
\text { (vital signs) or preemptive examination }\end{array}$ \\
\hline 2 & $\begin{array}{l}\text { What is the main problem (symptom) } \\
\text { of this patient? }\end{array}$ & $\begin{array}{c}\text { True or false symptoms, symptoms } \\
\text { of the eight major factors }\end{array}$ \\
\hline 3 & $\begin{array}{l}\text { What are all the causes covered by this } \\
\text { major symptom? }\end{array}$ & local, adjacent, systemic, and mental \\
\hline 4 & $\begin{array}{l}\text { What is the most likely diagnosis } \\
\text { of the patient? }\end{array}$ & $\begin{array}{l}\text { Common diseases and frequently } \\
\text { occurring diseases }\end{array}$ \\
\hline 5 & $\begin{array}{c}\text { Does the patient have any other } \\
\text { possible problems? }\end{array}$ & $\begin{array}{l}\text { Potentially life-threatening condition } \\
\text { (VINDICATE), adherence to treatment } \\
\text { and individuality }\end{array}$ \\
\hline
\end{tabular}




\section{A Symptom-Oriented Initial Emergency Diagnosis Model}

The initial diagnosis for the patient should be based on the patient's initial state, which is the symptom, not the disease. Any patient visits a hospital with a symptom or discomfort, and the first information the emergency physician gets from the patient is a symptom or sign of an acute attack, not a disease. Symptom oriented initial diagnosis mode is more in line with clinical practice, and symptoms are the "real world" of patients [11]. As early as the 1990s, people began to use the "symptom oriented" diagnosis mode for clinical teaching [12], and had achieved good results in the medical practice.

According to a symptom-oriented diagnosis model, we should first accurately judge the high-risk symptoms, and carry out "preemptive examination and diagnosis" or "preemptive treatment". For non-high-risk symptom, we do not emphasize the urgency of time and carry out "stratified titration" diagnosis model (Figure 1). It is one of the core strategies of emergency department to adopt different diagnosis and treatment methods according to different degrees of critical patients.

Secondly, because accurate judgment of symptoms is the premise of guiding inquiry and physical examination, it is necessary to judge the true and false symptoms and main symptoms. Sometimes, patients with multiple symptoms, emergency doctors must analyze and select the main symptoms as the guidance direction according to the changes of disease symptoms.

For example: hematemesis, first of all, we should judge the degree of high risk, how much blood loss, whether shock or not, then to judge the true and false of hematemesis, the patient showed hematemesis, but it may also be hemoptysis or throat wall bleeding, there may be systemic coagulation dysfunction. The eight elements of the symptoms and the physical examination should be used to verify the true or false hematemesis and the main symptoms, in order to avoid the risk of misdiagnosis or missed diagnosis.

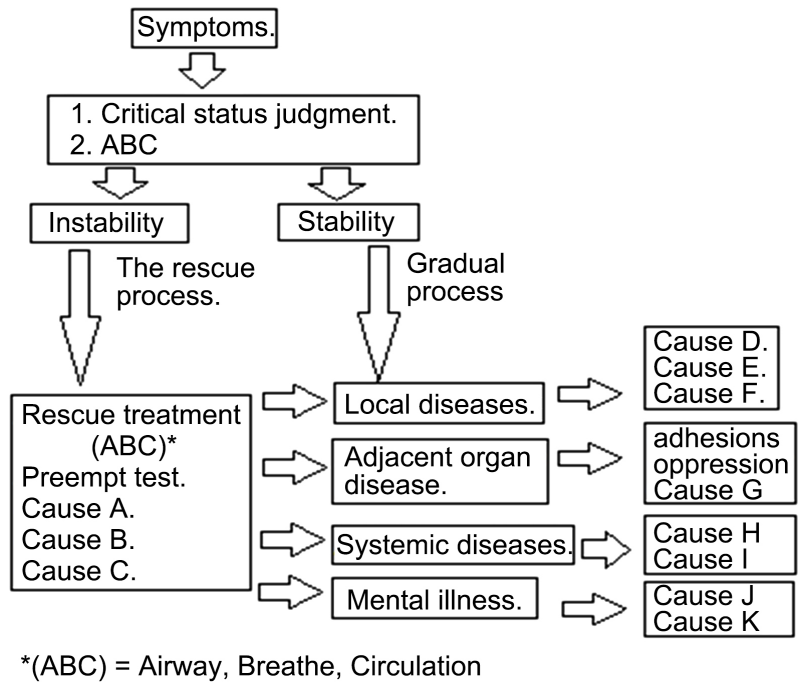

Figure 1. Emergency clinical decision flow chart. 


\section{A “Checklist" for the Differential Diagnosis}

As mentioned above, the symptom oriented initial diagnosis mode is in line with clinical practice and guides the next step of inquiry and physical examination. However, the symptoms of patients are often not directly from the primary disease, clinical manifestations do not represent one disease, even a group of clinical manifestations does not represent one disease, one disease may have multiple symptoms, multiple symptoms may be from one disease. The complexity of clinical manifestations is the difficult for decision of emergency doctors. There are so many differential diagnosis diseases, doctor can't remember hundreds of diseases and their symptoms or manifestations. Therefore, it is not easy for any doctor to think thoroughly, deeply and think carefully, especially for emergency doctors in a short time. How to think quickly to make an effective diagnosis has always been an issue. To begin to address this, herein a clinical symptom-oriented complete modular differential diagnosis scheme based on the concept of holistic medicine was developed. Four key directions according to the principle of anatomical positions (local, adjacent, systemic, and mental) were promulgated to support design of the top level of a modular scheme. The second and third levels of the protocol applied anatomical concepts to define subcategories. the list of differential diagnosis is not only easy to remember, but also provides a direction of thinking. Take chest pain as an example (Table 2): divide all the causes of "chest pain" into the above four broad categories, each of which has a structured secondary classification, such as local organ diseases including: cardiovascular disease, respiratory disease, mediastinal disease, chest wall disease; systemic disease secondary classification includes: hematological disease, bone tumor, metabolic immunity, poisoning and so on. This chect list not only accords with the principle of anatomical location of diagnosis, but also forms a mode of thinking, from local to whole, which effectively broadens the lateral thinking of emergency doctors and forms a fixed and systematic structured schemea to the diagnosis rather than fixing the diagnostic thinking to a specific disease [13]. Following the checklist and the principles of clinical thinking [14], combined with clinical experience, It is concise and clear to further guide physical examination and auxiliary examination for differential diagnosis without missing the key diseases. The checklist fits the principle of mind map [15], and it is more concise, flexible and it can avoid the thought rigidity that mind map may cause [16].

\section{The Idea of Dynamic Observation}

According to the thinking direction provided by the thinking list, a large number of clinical data was collected, such as medical history, physical examination, laboratory tests and so on, the evidence that accords with the objective reality was selected by removing the false things and retaining the real things to make a reasonable preliminary diagnosis. The initial diagnosis is generally subjective and must be screened and verified repeatedly according to the list of thinking. After initial diagnosis, necessary treatment was given. The treatment effect was 
Table 2. Checklist of causes of chest pain.

\begin{tabular}{|c|c|c|c|}
\hline Symptoms & Direction & Location & Causes of diseases \\
\hline & & & Angina pectoris, myocardial infarction \\
\hline & & Cardiovascular & aortic dissection \\
\hline & & diseases & Pulmonary embolism \\
\hline & & & Cardiomyopathy, pericarditis \\
\hline & & $\begin{array}{l}\text { Respiratory } \\
\text { diseases }\end{array}$ & $\begin{array}{l}\text { Spontaneous pneumothorax, hemothorax, } \\
\text { empyema, pneumonia, lung cancer, etc. } \\
\text { Pleuritis, pleural neoplasms. }\end{array}$ \\
\hline & & $\begin{array}{l}\text { Mediastinal } \\
\text { Diseases }\end{array}$ & $\begin{array}{l}\text { Mediastinitis, mediastinal tumor, hiatal } \\
\text { hernia, esophageal carcinoma }\end{array}$ \\
\hline & $\begin{array}{l}\text { Local organ } \\
\text { disease }\end{array}$ & & $\begin{array}{l}\text { Dermatitis, subcutaneous cellulitis, } \\
\text { myositis, etc. }\end{array}$ \\
\hline & & & intercostal neuralgia \\
\hline \multirow[t]{8}{*}{ Chest pain } & & $\begin{array}{l}\text { Chest wall } \\
\text { disease, }\end{array}$ & $\begin{array}{l}\text { Chest and abdominal wall suppository } \\
\text { superficial phlebitis }\end{array}$ \\
\hline & & & Herpes zoster, etc. \\
\hline & & & $\begin{array}{l}\text { Costal cartilage inflammation, rib fracture, } \\
\text { cervical or thoracic diseases, etc. }\end{array}$ \\
\hline & & Spinal spine & $\begin{array}{l}\text { Vertebra disease can lead to precardiac } \\
\text { pain, known as "cervical angina" }\end{array}$ \\
\hline & & & Reflux esophagitis, etc. \\
\hline & $\begin{array}{l}\text { Adjacent organ } \\
\text { diseases }\end{array}$ & $\begin{array}{l}\text { Abdominal } \\
\text { diseases }\end{array}$ & $\begin{array}{l}\text { abscess, liver abscess, splenic infarction, } \\
\text { liver cancer, etc. }\end{array}$ \\
\hline & General diseases & & $\begin{array}{l}\text { acute leukemia, multiple myeloma, } \\
\text { ankylosing spondylitis. }\end{array}$ \\
\hline & Mental disorders & Cardiac neurosis & Cardiac neurosis, etc. \\
\hline
\end{tabular}

also one of the methods to verify whether the initial diagnosis was correct or not, If the effect was not good, the correctness of the initial diagnosis would be in turn rechecked again.

Above all, it can be seen that the clinical decision-making process is a dynamic. It is not easy for emergency physicians to exclude life-threatening conditions in a short period. Clinical thinking has Uncertainty, and coupled with human-induced thinking defects, further dynamic observation is an essential step to verify the correctness of the original diagnosis and treatment as the disease itself develops. Constantly verify, supplement, and modify the original diagnosis, the cycle is repeated so that the more correct diagnosis is obtained [17]. This also fits in with the dynamic of clinical thinking [14]. 
Whether the patient is hospitalized or not, dynamic observation is a routine procedure of emergency. It is not only a necessary step in emergency clinical decision-making, but also a reflection of critical thinking. It is as important as drugs and laboratory tests, and even more important.

\section{Summary}

The implementation of homogenized medical treatment is an important link in optimizing medical resources and realizing sustainable medical reform [1]. At present, the rapid development of specialist alliance aims to promote the tiered medical services, the homogenization of medical services is one of the key measures [18]. As the window of the hospital and the first step to save people, the training of emergency doctors needs a long time which is very different from other specialties. The homogenization of emergency medical services can effectively enhance the service ability of primary medical institutions. Therefore, it is of great significance to explore the homogenization of clinical decision-making of emergency. Taking symptom as the starting point, establishing the process thinking of symptom-oriented, guiding the diagnosis direction with "thinking list", widening the lateral thinking of emergency doctors, and applying system analysis to clinical decision-making, not only accelerate the training young emergency doctors [5], but also may achieve the homogenization of emergency clinical decision-making effect.

\section{Acknowledgements}

Jianguo Li had the idea for the article, Huijun Qi wrote the article, Zhangshun Shen, Hui Guo performed the literature search, and Jianguo $\mathrm{Li}$ is the guarantor.

\section{Conflicts of Interest}

The authors declare no conflicts of interest regarding the publication of this paper.

\section{References}

[1] Lai, W., Xu, H.F. and Wan, W. (2015) View of China's Major Task in Medium and Long Term Healthcare Reform: Promoting Medical Treatment Homogenization. Chinese Hospital Management, 35, 1-3.

[2] Wu, D. (2015) The Principle and Method of Clinical Decision-Making. Chinese Journal of Diagnostics (Electronic Edition), No. 4, 235-239.

[3] Chen, P. J., Wang, Z. Y., Jia, Y. P. et al. (2019). Exploration and Thinking of the Construction of Zhujiang Medical Specialism Alliance. Chinese Hospital Management, 39, 76-77.

[4] Wang, P.Y. (2007) Distinctive Diagnosis of Emergency Clinical Thinking-Stepping. World Journal of Critical Care Medicine, 4, 1828.

[5] Quan, Y. (2016) Analysis on the Thinking of Clinical Diagnosis and Treatment of Primary Doctor Emergency. Knowledge of Prevention and Treatment of Cardiovascular Diseases, No. 2, 159-160. 
[6] Guo, H., Zhao, Q. and Li, J.G. (2019) Discussing How Medical Humanities Enter into Clinic from the Angle of Clinical Thinking. Medicine and Philosophy, 40, 17-20.

[7] Li, J.G., Lv, C., Zhao, Q., et al. (2019) A Brief Discussion on Uncertainty of Clinical Thinking and Coping Strategies. Medicine and Philosophy, 40, 14-17.

[8] Yu, X.Z. (2016) Blessing China Emergency. Chinese Journal of Emergency Medicine, 25,2 .

[9] Ding, B., Meng, Q.Y., Chen, X.H., et al. (2016) Misdiagnosis of Triple Sign of Acute Chest Pain in China (2004-2013). China Emergency Medicine, 36, 817-823.

[10] Kohn, L.T., Corrigan, J.M. and Donaldson, M.S. (1999) To Err Is Human: Building a Safer Health System. National Academy Press, Washington DC.

[11] Du, Z.Z. (2017) Clinical Judgment: Based on the Real World of the Patient. Medicine and Philosophy $(A), 8,1-5,20$.

[12] Mandin, H., Harasym, P., Eagle, C., et al. (1995) Developing a "Clinical Presentation" Curriculum at the University of Calgary. Academic Medicine, 70, 186-193. https://doi.org/10.1097/00001888-199503000-00008

[13] Huang, Y.C. (2017) A Light of Operation. Electronic Industry Press, Beijing, 69-79.

[14] Zhao, Q., Guo, H., Shen, Z.S., et al. (2019) Discussion on the Nature and Principle of Clinical Thinking. Medicine and Philosophy, 40, 15-19.

[15] Zhang, Y.Z., Xu, J., Sun, F., et al. (2018) A Brief Discussion on the Auxiliary Application of Mind Map in Clinical Decision-Making. Clinical Misdiagnosis and Mistreatment, 31, 5-8.

[16] Arto, G. (2017) List Revolution. Translated by Wang Jiayi, Beijing United Press, Beijing, 46-56.

[17] Wan, X.H. and Lu, X.F. (2018) Diagnostics. People's Health Publishing House, Beijing, 587-591.

[18] Xie, Y., Yu, Y.M., Yu, R.F., et al. (2017) Analysis of Hierarchical Diagnosis and Treatment Development Progress and Policy Evolution in China. Chinese Hospital Management, 37, 24-27. 